\title{
Effects of geometric particle sizes of wood flour on strength and dimensional properties of wood plastic composites
}

\section{N. I zekor*, S. O. A miandamhen and O. S. Agbarhoaga}

Department of Forestry and Wildlife, University of Benin, P.M.B. 1154, Benin City, NIGERIA.

*Corresponding author. E-mail: nosakhare.izekor@uniben.edu

Received: March 21, 2013; Revised received; April 25, 2013, Accepted: M ay 10, 2013

Abstract: The effect of different wood flour sizes on strength and dimensional properties of wood-plastic composites were examined. Wood flour of different particle sizes viz; $1.00 \mathrm{~mm}, 2.00 \mathrm{~mm}$ and $>2.00 \mathrm{~mm}$ were compounded with recycled low-density polyethylene (LDPE) at different wood/plastic ratio of 1: 1, 2: 3 and 3: 2 . The results obtained showed that wood flour size $>2.00 \mathrm{~mm}$ has the highest MOR and MOE values of $1.206 \mathrm{~N} \mathrm{~mm}^{-2} \mathrm{and}_{2484.72 \mathrm{Nmm}^{-2}}$ while wood flour size of $1.00 \mathrm{~mm}$ had the lowest MOR and MOE values of $0.505 \mathrm{Nmm}^{-2}$ and $2195.89 \mathrm{Nmm}^{-2}$ respectively. Also the results of the physical properties showed that wood flour size of $1.00 \mathrm{~mm}$ had the lowest thickness swelling percentage with mean values of $0.28 \%$ and $2.08 \%$ while water absorption percentage has mean values of $0.91 \%$ and $10.58 \%$ after 2 hours and 24 hours of water immersion respectively. It was observed that wood flour size of $2.00 \mathrm{~mm}$ and particle size $>2.00 \mathrm{~mm}$ had the highest thickness swelling and water absorption percentages. This showed that strength properties of wood plastic composites increased with increased particle sizes whereas its dimensional properties increased with decreased particle sizes. The results of analysis of variance carried out on mechanical and physical properties showed that particle sizes and wood/plastic ratio had a significant effect on the mechanical and physical properties of wood plastic composites $(p \leq 0.05)$.

Keywords: Dimensional stability, Geometric particle sizes, Low-density polyethylene, Wood flour, Wood plastic composite

\section{INTRODUCTION}

There have been a considerable increase in recent years on the production and application of wood-plastic composites (WPCs). Their properties and environmental advantages have made them a good choice for many applications (Wang and Zhang, 2007; Bledzki and Faruk, 2004). WPCs are made by combining wood and thermoplastic polymer, which results in a composite that combines the best properties of both components (Yang et al., 2007). Wood often imparts strength and stiffness and is biodegradable, while the plastics afford ease of formation and moisture resistance (Bentsson et al., 2005). WPC are widely used in USA, the most common type of such panels are produced by mixing wood flour and plastics to produce material that can be processed similar to $100 \%$ plastic based products (Charrier, 1991; Groom et al., 1996; Ballerini, 2004).

Polyethylene (PE) is a popular choice as polymer matrix, with several studies focusing on properties of lowdensity polyethylene (LDPE)-wood composites (Bentsson et al., 2005; Kuan et al., 2006). The geometric particle size of the wood used in WPCs affects the properties of the WPCs (Bledzki et al., 1998). But little work is documented on the effect of geometic particle size on low-density polyethylene wood composites, ISSN : 0974-9411 (Print), 2231-5209 (Online) All Rights Reserved ๔ Applied and Natural Science Foundation www.ansfoundation.org particularly the ubiquitous polyethylene materials (sachet nylon) in the world today. This polyethylene is a source of potential raw materials for the production of WPCs. They also contribute greatly to environmental pollution through littering of road sides, blocking of drainage system, river and oceans. The recycle of this plastic waste has led into new innovating building materials, which has led to a major breakthrough in the area of environmental control and structural materials improvement.

The use of WPCs have many advantages over the other particle boards. Such advantages are extreme moisture resistant with low or less thickness swelling, extreme resistance to fungal attack, improved strength properties, environmental friendly, highly elastic with high impact resistance (English and Falk, 1995). The sustainability of this technology becomes more attractive when the low cost and high availability of fine particles of wood waste is considered. These composites are transformed by extrusion processes to obtain applications including profiles, sheathings, decking, roof tiles, and window trims, with improved thermal and creep performance compared with unfilled plastics (English and Falk, 1995; Verhey et al., 2002). In general, properties of WPCs depend on various factors, including the inherent properties of the 
constituent materials, interactions among these materials and processing methods. The amount, geometric sizes, and surface characteristics of the wood component and the interfacial properties between the wood and plastic influence the mechanical and physical properties of the WPCs.

There is a gradual increase in the trend of research on WPCs in Nigeria with the use of different plastic binders, being assessed. The effect of some wood species on strength properties of WPCs has also been investigated. Ajigbon and Fuwape (2005); Fuwape and Aina (2008) investigated the possibility and potentials of tropical wood species and agro-residue for the production of wood plastic composites in Nigeria, using manually fabricated compounding hot press machine.

The objective of the study was to determine the best suitable size of wood flour that will be required for the production of wood plastic composites as well as determine the effects of these geometric particle sizes of wood on strength and dimensional properties of wood plastic composites.

\section{MATERIALS AND METHODS}

Study area: The study was carried out at the wood product research laboratory of Forestry Research Institute of Nigeria Ibadan, Oyo State. The state is located between latitude $\mathrm{N} 7^{\circ} 23^{\prime}$ and E $3^{\circ} 54^{\prime}$. Sawdust of C eiba pentandra wood was collected from the sawmill section of the Forest Products Development and Utilization Department of the institute. The sawdust was air dried to a constant moisture content of $12 \%$ in a controlled laboratory. Thereafter it was sieved to obtain the different geometric particle sizes of $1.00 \mathrm{~mm}, 2.00 \mathrm{~mm}$ and above $2.00 \mathrm{~mm}$, using the standard laboratory sieve. The Plastic binder used was the low-density polyethylene (LDPE) plastic (water sachets) collected within the premises of University of Benin campus in Benin City. The lowdensity polyethylene plastics were shredded into flakes using pelletizing milling machine in the laboratory.

The sawdust and the LDPE plastic was weighed using electronic weighing balance while appropriate quantities of the materials were thoroughly mixed and formed into a mat in the production plate with a dimension of $300 \mathrm{~mm} \mathrm{x}$ $300 \mathrm{~mm} \times 6 \mathrm{~mm}$. The WPC boards were produced using fabricated hot press compounding machine at a temperature of $100-120^{\circ} \mathrm{C}$ for a period of 10 minutes under constant pressure of $1.23 \mathrm{~N} / \mathrm{mm}^{2}$. Samples were produced using the following production factors $0.8 \mathrm{Kg} / \mathrm{m}^{3}$ (constant) geometric particle sizes of $1.00 \mathrm{~mm}, 2.00 \mathrm{~mm}$ and above $2.00 \mathrm{~mm}$ with sawdust/plastic ratio of $1: 1,2: 3$ and $3: 2$. WPC boards measuring $200 \mathrm{~mm}$ x $200 \mathrm{~mm}$ were formed after trimming. Test samples were collected from each board for physical and mechanical properties determination. The experiment was carried out as three factor factorial in a completely randomized designed. Mechanical properties determination was carried out in accordance with ASTM standard (2004). The static bending test from which the modulus of rupture (MOR) and modulus of elasticity (MOE) were evaluated was carried out using specimen size 194 x 50 x $6 \mathrm{~mm}$. The test was a centre-loading supported on a span of $280 \mathrm{~mm}$ while the force was applied on the radial face at mid span using a loading rate of $0.1 \mathrm{~mm} / \mathrm{minute}$ on a Hounsfield Tensiometer Machine. The MOR was calculated from the maximum load at which the test sample failed. The MOE was calculated using load to deflection curve plotted on a graph by the Tensiometer Machine.

Physical properties determination was carried out using test samples measuring $100 \mathrm{~mm} \times 100 \mathrm{~mm} \times 6 \mathrm{~mm}$. The thickness of the test samples was determined using electronic digital caliper while the weight was determined, using an electronic weighing balance before and after water immersion. The test specimens were submerged in water bath in a horizontal position to the depth of $25 \mathrm{~mm}$ for a period of 2 hours and 24 hours respectively.

\section{RESULTS AND DISCUSSION}

M echanical properties: The results obtained for MOR of wood plastic composites are presented (Table 1). The mean values obtained for wood plastic composites produced from wood particle size of $1.00 \mathrm{~mm}$ were 0.524 , 0.352 and $0.640 \mathrm{~N} \mathrm{~mm}^{-2}$. MOR values of wood plastic composites produced from particle size of $2.00 \mathrm{~mm}$ were $0.620,0.563$ and $0.742 \mathrm{~N} \mathrm{~mm}^{-2}$ while that of particle size above $2.00 \mathrm{~mm}$ were $1.285,0.846$, and $1.486 \mathrm{~N} \mathrm{~mm}^{-2}$. Similarly, the MOE values for wood plastic composites produced from particle sizes of $1.00 \mathrm{~mm}$ were $2157.26,774.35$ and $3656.06 \mathrm{~N} \mathrm{~mm}^{-2}$. MOE values of wood plastic composites of $2.00 \mathrm{~mm}$ particle size were $2165.28,1193.11$ and $3653.46 \mathrm{~N}$ $\mathrm{mm}^{-2}$ while the MOE values of wood plastic composites produced from particle size above $2.00 \mathrm{~mm}$ were 1400.84 , 903.33 and $5149.98 \mathrm{~N} \mathrm{~mm}^{-2}$. The results showed that mechanical properties increased with increased particle sizes (Table 1). Wood flour size of above $2.00 \mathrm{~mm}$ has the highest MOR and MOE values of $1.206 \mathrm{~N} \mathrm{~mm}^{-2}$ and $2484.72 \mathrm{~N} \mathrm{~mm}^{-2}$ respectively. This was followed by wood flour sizes of $2.00 \mathrm{~mm}$ while wood flour size of $1.00 \mathrm{~mm}$ had the lowest MOR and MOE values of $0.505 \mathrm{~N} \mathrm{~mm}^{-2}$ and $2195.89 \mathrm{~N} \mathrm{~mm}^{-2}$ respectively. These findings agree with previous results reported in literature (Zaini et al., 1995; Liew et al., 2000; Stark and Rowlands, 2003;). The reasons for this could be attributed to the interaction between the hydrophilic wood flour and the hydrophobic polyethylene matrix (Zaini et al., 1995; Liew et al., 2000; Stark and Rowlands, 2003). Increase in mechanical properties of wood plastic composites were found to correspond with increase in aspect ratio, length/width ratio of wood flour, (Stark and Rowlands, 2003). The larger 
Table 1. Mechanical properties of wood plastic composites.

\begin{tabular}{lccc}
\hline \multirow{2}{*}{ Particle sizes } & & \multicolumn{2}{c}{ M echanical properties } \\
\cline { 2 - 4 } & $\begin{array}{c}\text { M ixing ratio } \\
\text { wood : plastic }\end{array}$ & M OR $\left(\mathrm{N} \mathrm{mm}^{-2}\right)$ & M OE $\left(\mathrm{N} \mathrm{mm} \mathrm{m}^{-2}\right)$ \\
\hline $1.00 \mathrm{~mm}$ & $1: 1$ & $0.524 \pm 0.020$ & $2157.26 \pm 49.48$ \\
& $2: 3$ & $0.352 \pm 0.028$ & $774.35 \pm 47.85$ \\
$2.00 \mathrm{~mm}$ & $3: 2$ & $0.640 \pm 0.039$ & $3656.06 \pm 411.53$ \\
& $1: 1$ & $0.620 \pm 0.018$ & $2165.89 \pm 65.79$ \\
$22.00 \mathrm{~mm}$ & $2: 3$ & $0.563 \pm 0.017$ & $1193.11 \pm 3.93$ \\
& $3: 2$ & $0.742 \pm 0.050$ & $3653.46 \pm 77.69$ \\
& $1: 1$ & $1.285 \pm 0.122$ & $1400.84 \pm 17.23$ \\
& $2: 3$ & $0.846 \pm 0.050$ & $903.33 \pm 95.35$ \\
\hline
\end{tabular}

Table 2. Analysis of variance for mechanical properties of wood plastic composites.

\begin{tabular}{|c|c|c|c|c|c|c|c|}
\hline \multirow[t]{2}{*}{ Sources of variance } & \multirow[t]{2}{*}{$\mathrm{df}$} & \multicolumn{2}{|c|}{ Fcal } & \multirow{2}{*}{\multicolumn{2}{|c|}{ Ftab }} & \multicolumn{2}{|c|}{ Significant } \\
\hline & & MOR & MOE & & & MOR & MOE \\
\hline Particle sizes(S) & 2 & 481.25 & 7.45 & 3.5 & & $0.000 *$ & $0.004 *$ \\
\hline Mixing ratio(MR) & 2 & 120.38 & 962.71 & 3.5 & & $0.000 *$ & $0.000 *$ \\
\hline $\mathrm{S} \times \mathrm{MR}$ & 4 & 19.13 & 54.89 & 2.9 & & $0.000 *$ & $0.000 *$ \\
\hline Error & 18 & & & & & & \\
\hline Total & 26 & & & & & & \\
\hline \multicolumn{3}{|c|}{ *significant $(\mathrm{P}<0.05)$ probability level } & \multirow{12}{*}{\multicolumn{5}{|c|}{$\begin{array}{l}\text { the wood flour particle sizes, the larger the stress } \\
\text { concentrations along the naturally weak interface of the } \\
\text { hydrophilic wood flour and hydrophobic polypropylene } \\
\text { (Stark and Rowlands, 2003). Notched impact energy } \\
\text { increased with increasing particle size, crack propagation } \\
\text { occurred at the polypropylene/wood flour interface as a } \\
\text { result of the poor interface between the hydrophilic wood } \\
\text { flour and the hydrophobic polypropylene. Consequently, } \\
\text { composites made with larger wood flour particles had } \\
\text { higher notched impact capacity (i.e., higher critical crack } \\
\text { propagation energy) as a result of the increase in fracture } \\
\text { surface area (Stark and Rowlands, 2003). } \\
\text { The mixing ratio (wood/plastic) also affects the } \\
\text { mechanical properties of WPC produced independently }\end{array}$}} \\
\hline \multicolumn{3}{|c|}{$\begin{array}{l}\text { Table 3. Duncan new multiple range test for modulus of rupture } \\
\text { and modulus of elasticity of wood plastic composites. }\end{array}$} & & & & & \\
\hline Particle sizes & MOR & MOE & & & & & \\
\hline $1.00 \mathrm{~mm}$ & $0.5053^{\mathrm{c}}$ & $21995.89^{b}$ & & & & & \\
\hline $2.00 \mathrm{~mm}$ & $0.6416^{\mathrm{b}}$ & $2337.28^{\text {a b }}$ & & & & & \\
\hline$\geq 2.00 \mathrm{~mm}$ & $1.2060^{\mathrm{a}}$ & $2484.7^{\mathrm{a}}$ & & & & & \\
\hline \multirow{2}{*}{\multicolumn{3}{|c|}{$\begin{array}{l}\text { Mixing ratio } \\
\text { Wood : Plastic }\end{array}$}} & & & & & \\
\hline & & & & & & & \\
\hline \multirow{3}{*}{$\begin{array}{l}1: 1 \\
2: 3 \\
3: 2\end{array}$} & $0.8097^{\mathrm{b}}$ & $1907.79^{b}$ & & & & & \\
\hline & $0.587^{\mathrm{c}}$ & $956.93^{c}$ & & & & & \\
\hline & $0.9561^{\mathrm{a}}$ & $4153.17^{\mathrm{a}}$ & & & & & \\
\hline \multicolumn{3}{|c|}{$\begin{array}{l}\text { Means in columns with the same superscript are not } \\
\text { significantly different }(p<0.05)\end{array}$} & & & & & \\
\hline \multicolumn{8}{|c|}{ Table 4. Physical properties of wood plastic composites. } \\
\hline \multirow[b]{2}{*}{ Particle sizes } & & \multicolumn{6}{|c|}{ Physical properties } \\
\hline & $\begin{array}{l}\text { xing ratio } \\
\text { d : plastic }\end{array}$ & TS\% 2 hours & $\mathrm{TS} \%$ & ars & W A \% & 2hours & W A \% 24hours \\
\hline $1.00 \mathrm{~mm}$ & $1: 1$ & $0.29 \pm 0.01$ & 1.85 & & 0.91 & \pm 0.02 & $12.26 \pm 1.56$ \\
\hline \multirow{5}{*}{$2.00 \mathrm{~mm}$} & $2: 3$ & $0.23 \pm 0.02$ & 1.34 & & 0.73 & +0.02 & $6.81 \pm 0.60$ \\
\hline & $3: 2$ & $0.31 \pm 0.04$ & 3.04 & & 1.08 & +0.09 & $12.58+4.15$ \\
\hline & $1: 1$ & $0.33 \pm 0.01$ & 2.75 & & 0.99 & \pm 0.01 & $15.00 \pm 1.60$ \\
\hline & $2: 3$ & $0.26 \pm 0.01$ & 1.44 & & 0.78 & \pm 0.01 & $7.41 \pm 1.97$ \\
\hline & $3: 2$ & $0.39 \pm 0.02$ & 3.18 & & 1.26 & \pm 0.07 & $15.69 \pm 2.63$ \\
\hline \multirow{3}{*}{$\geq 2.00 \mathrm{~mm}$} & $1: 1$ & $0.42 \pm 0.02$ & 4.85 & & 1.07 & \pm 0.11 & $18.37 \pm 1.01$ \\
\hline & $2: 3$ & $0.30 \pm 0.01$ & 3.93 & & 0.82 & +0.02 & $8.83 \pm 2.04$ \\
\hline & $3: 2$ & $0.55 \pm 0.03$ & 6.39 & & 1.38 & \pm 0.33 & $20.82 \pm 1.57$ \\
\hline
\end{tabular}


Table 5. Analysis of variance for physical properties of wood plastic composites.

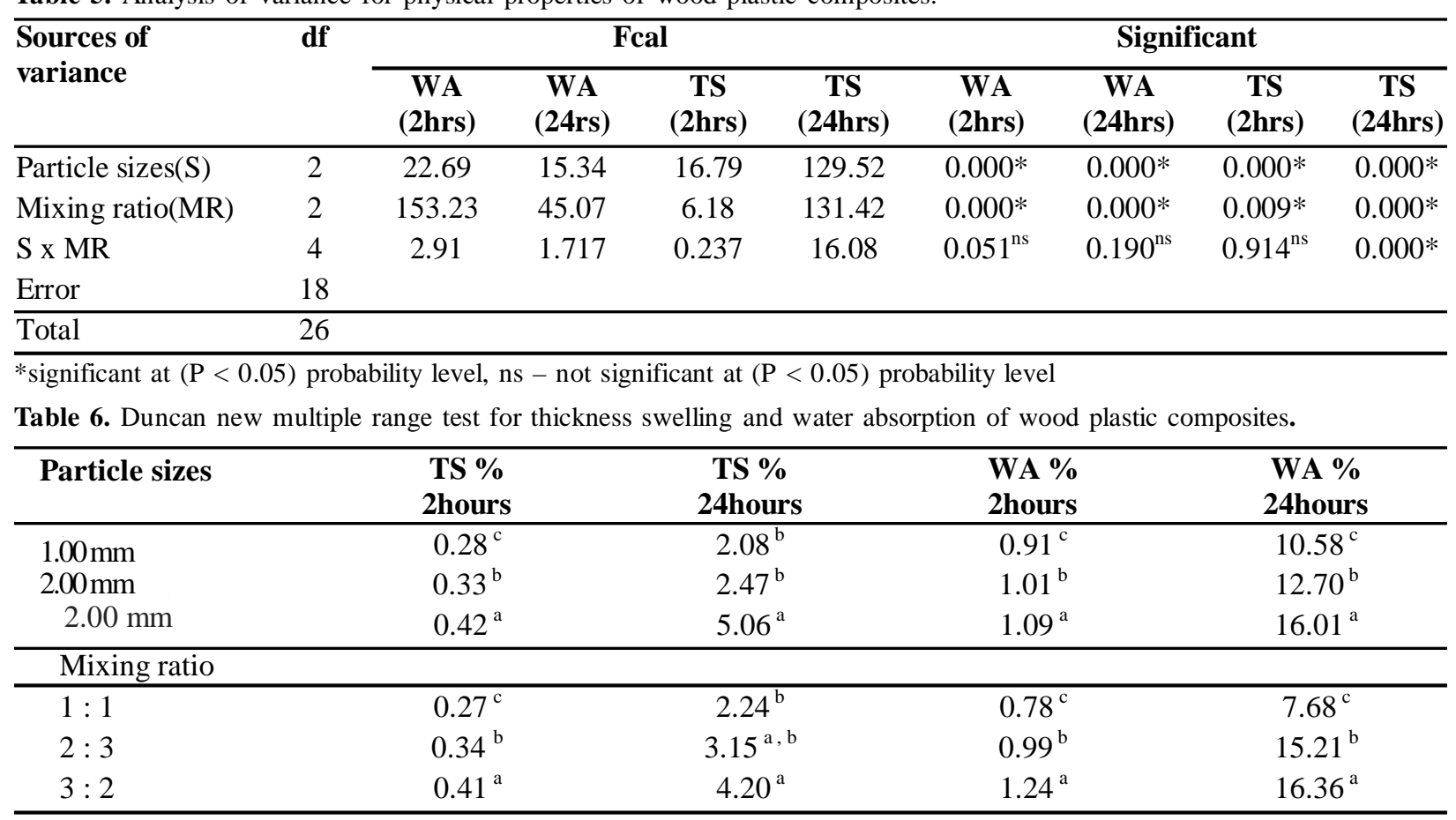

from the particle sizes. The results presented (Table 1) showed that mechanical properties increased with increase in the proportion of wood with respect to plastic. Wood/plastic ratio 2:3 has the lowest MOR and MOE values of 0.587 and $956.93 \mathrm{~N} \mathrm{~mm}^{-2}$ respectively. This was followed by wood/plastic ratio 1:1 while wood/plastic ratio 3:2 has the highest MOR and MOE values of 0.956 and $4153.17 \mathrm{~N} \mathrm{~mm}^{-2}$ respectively. This observation may be as a result of the higher strength properties of wood compared to the plastic matrix. Similar observation has also been reported with polymer, increase in polymer content resulted in decrease in tensile modulus and as polymer decreases, wood flour increases, and ultimately resulting in observed increased in modulus of elasticity (Liew et al., 2000)

The results of analysis of variance carried out at 5\% probability level to test for significant differences among particle sizes and mixing ratio of wood plastic composites are presented (Table 2). The results showed there were significant differences in wood plastic composites produced from different particle sizes and mixing ratio ( $p$ $<0.05)$. Also the interaction between particle sizes and mixing ratio were significant at $5 \%$ probability level.

Duncan New Multiple Range Test was used in the separation of means at 5\% probability level (Table 3). The results showed that the mean values obtained for MOR and MOE of wood plastic composites produced from different wood particle sizes and mixing ratio were significantly different $(\mathrm{p}<0.05)$.

Physical properties: The results obtained for the physical properties of wood plastic composites are presented
(Table 4.4). The mean values of thickness swelling of wood plastic composites produced from particle size of $1.00 \mathrm{~mm}$ after immersion in water for 2 hours and 24 hours respectively were $0.29,0.23,0.31 \%$ and $1.85,1.34,3.04 \%$ while the mean values of thickness swelling produced from particle size of $2.00 \mathrm{~mm}$ were $0.33,0.26,0.39 \%$ and $2.75,1.44,3.18 \%$ respectively. The mean values of thickness swelling of wood plastic composites produced from particle size of above $2.00 \mathrm{~mm}$ were $0.42,0.30,0.55 \%$ and $4.85,3.93,6.39 \%$ respectively. Similarly, the mean values obtained for water absorption of wood plastic composites produced from particle size of $1.00 \mathrm{~mm}$ after immersion in water for 2 hours and 24hours respectively were $0.91,0.73,1.08 \%$ and $12.26,6.81,12.58 \%$ respectively. The mean values obtained for particle size of $2.00 \mathrm{~mm}$ were $0.99,0.78,1.26 \%$ and $15.00,7.41,15.69 \%$ respectively while the mean value of water absorption for wood plastic composites produced from particle size of above $2.00 \mathrm{~mm}$ were $1.07,0.82,1.38 \%$ and $18.37,8.83$, $20.82 \%$ respectively. The results showed that thickness swelling and water absorption of wood plastic composites increased with increase in particle sizes. Therefore, the smaller the wood flour size, the better the dimensional stability of wood plastic composites.

The results in Table 4 showed the effects of wood/plastic ratio on physical properties of the board produced independently on particle sizes. The results showed that water absorption and thickness swelling of wood plastic composites increased with increased reinforcing filler (wood flour). This situation could be attributed to the hydrophilic nature of wood flour and an increase in water 
sorption is expected from wood plastic composites with more wood flour content. As the wood flour loading increased, the cellulose content also increased resulting in the absorption of more water (George et al., 2001; Khan et al., 2003; Adhikary et al., 2008; Ghasemi and Kord 2009). This showed that the higher the quantity of plastic/ wood ratio in wood plastic composites, the better the moisture resistant and its dimensional stability.

The results of analysis of variance carried out at $5 \%$ probability level to test for significant differences among particle sizes and mixing ratio on physical properties of wood plastic composites are presented in Tables 5 . The results showed that, there were significant differences in wood plastic composites produced from different particle sizes and mixing ratio. However the interaction between particle sizes and mixing ratio were not significant at $5 \%$ probability level except for thickness swelling which showed some level of significance after been immersed in water for 24 hours.

Duncan New Multiple Range Test was used in the separation of means at $5 \%$ probability level (Table 6). The results showed that thickness swelling and water absorption of wood plastic composites produced from different wood particle sizes and mixing ratio were significant.

\section{Conclusion}

The properties considered in investigating the effects of geometric particle sizes of wood flour on strength and dimensional stability of wood plastic composites were those of modulus of rupture, modulus of elasticity, thickness swelling and water absorption. The study showed that wood flour sizes of $2.00 \mathrm{~mm}$ and wood/plastic ratio $1: 1$ produced the best effect on the strength properties and dimensional stability of wood plastic composites boards. Wood flour sizes $1.00 \mathrm{~mm}$ and wood/ plastic ratio 2:3 had low strength properties and high dimensional stability while wood flour sizes above $2.00 \mathrm{~mm}$ and wood/plastic ratio 3:2 had high strength properties but low dimensional stability.

Therefore an increase in geometric particle sizes and the amount of particle in wood plastic composites resulted in a corresponding increase in strength properties and a decrease in dimensional stability was due to the hygroscopic nature of the wood component.

\section{REFERENCES}

Adhikary, K. B., Pang, S. and Staiger, M. P. (2008). Long term moisture absorption and thickness swelling behaviour of recycled thermoplastics reinforced with $\mathrm{P}$ inus radiata sawdust. Chemical Engineering J ournal 142: 190 - 198

Ajigbon A.A. and Fuwape J.A. (2005): Strength and dimensional properties of plastic composite

boards produced from Terminalia superba. Proceeding on conventional development in Agriculture, School of
Agriculture and Agricultural Technology, Federal University of Technology, Akure 242 - 244pp.

ASTM (2004). American society for testing and materials. Standard Methods for Testing Tensile Properties of Plastics ASTM D 638-03

Ballerini, A. (2004). F ondef project. Development of chemical additives from tall oil to improve the compatibility of woodplastic composites. http://www.conicyt.cl/bases/fondef.

Bentsson, M., Gatenholm, P. and Oksman, K. (2005). The effect of cross linking on the properties of polyethylene/ wood flour composites. Composites Science and Technology, 65: 1468 - 1479.

Bledzki, A. K. and Faruk, O. (2004). Creep and impact properties of wood fiber-polypropylene composites: Influence of Temperature and Moisture Content. Composites Science and Technology 64: $693-700$.

Bledzki, A. K., Gassan, J. and Thesis, S. (1998). Wood-filled thermoplastic composites. Mechanics of Composite Materials 34: $563-568$.

Charrier, M. P. (1991). Polymeric materials and processing. Plastics, elastomers, and composites. Oxford University Press, New York.

English, B. W, and Falk, P. (1995). Factors that affect the application of wood fiber plastic composites. Wood fiber plastic composites. Forest Products Society. Proceeding No. 7293: 189 - 194pp

Fuwape, J. A. and Aina, K. S. (2008). Effect of weathering on strength and physical properties of wood plastic composites produced from $G$ melina arborea. Nigerian Journal of Forestry 38: 62- 73 .

George, J., Sreekala, M. S. and Thomas, S. (2001). A review on interface modification and characterization of natural fibre reinforced plastic composites. Journal of Polymer

Engineering and Science 41 (9): 1471 - 1485.

Ghasemi, I. and Kord, B. (2009). Longterm water: Absorption behaviour of polypropylene wood flour organoclay hybrid nanocomposite. Iranian Polymer J ournal 18 (9): 683 - 691.

Groom, L., Shaler, S. M. and Mott, L. (1996). Mechanical properties of lignocellulosic fibres. Wood fiber Plastic Composites, Forest Products Society, Masidon, Wisconsin 33 - 40 pp.

Khan, M. A., Islam, M. N., Alam, M. K. and Zaman, M. A. (2003). Study of water absorption behaviour in wood plastic composites by using neutron radiography techniques. J ournal of Plastic Technology and Engineering 42: 925 934.

Kuan, C. F., Kuan, H. C., Ma, C. C. and Huang, C. H. (2006). Mechanical, thermal and morphological Properties of watercross linked wood flour reinforced linear low

density polyethylene composites. Composites. Part A 37: 1696 - 1707.

Liew, K. C., Harum, J., Tahir, P. M., Yusoff, M. N. M. and Dahlan, K. Z. M. (2000). Properties of rubber wood flourpolypropylene composites blended at different fibre contents and fibre size fractions. J ournal of Tropical F orest Products. 6 (1): $21-27$.

Stark, N. M. and Rowlands, R. E. (2003). Effects of wood fiber characteristics on mechanical properties of wood/ Polypropylene composites. Journal of Wood and Fiber Science. 35 (2):167-174. 
Verhey, A. S. and Laks, E. P. (2002). Wood particle size affects the decay resistance of woodfiber/thermoplastic composites. Forest Products J ournal 52 (11/12): $78-81$.

Wang, S. and Zhang, A. (2007). Chemical characterization of smoke from the production process of wood-plastic composites. F orestry Studies in China 9: 57 - 62.

Yang, H., Wolcott, M. P., Kim, H. S., Kim, S. and Kim, H. J. (2007). Effect of different compatibilizing agents on the mechanical properties of lignocellulosic material filled polyethylene bio-composites. Composites Structure 79: 369 $-375$.

Zaini, M. J., Fuad, M.Y., Ismail, Z., Mansor, M.S. and Mustafah, J. (1995). The effect of filler content and size on the mechanical properties of polypropylene/oil palm wood flour composites. Polymer International J ournal. 40: 51 55. 